\title{
Foramen Magnum Meningiomas: A Report of 10 Cases and Literature Review
}

\author{
Abidin Murat GEYIK ${ }^{1}$, Serhat PUSAT ${ }^{2}$, Mehmet ALPTEKIN³ ${ }^{3}$ Berna KAYA UGUR ${ }^{4}$, Sirma GEYIK ${ }^{5}$, Ali NEHIR ${ }^{1}$, \\ Ibrahim ERKUTLU ${ }^{1}$
}

\begin{abstract}
${ }^{1}$ Gaziantep University, Faculty of Medicine, Department of Neurosurgery, Gaziantep, Turkey
${ }^{2}$ Health Science University, Sultan Abdulhamid Training and Research Hospital, Department of Neurosurgery, Istanbul, Turkey

${ }^{3}$ Gaziantep Private Live Hospital, Department of Neurosurgery, Gaziantep, Turkey

${ }^{4}$ Gaziantep University, Faculty of Medicine, Department of Aaesthesiology and Reanimation, Gaziantep, Turkey

${ }^{5}$ Gaziantep University Faculty of Medicine, Department of Neurology, Gaziantep, Turkey
\end{abstract}

Corresponding author: Serhat PUSAT pusatserhat@yahoo.com

\section{ABSTRACT}

AIM: Surgeries of foramen magnum meningiomas are highly complex due to their close proximity to vascular and neural structures. This study presents the findings and surgical results of foramen magnum meningioma surgeries performed by us.

MATERIAL and METHODS: Ten patients operated between 2014 and 2019 were retrospectively analyzed in terms of age, gender, neurological examination, and postoperative status. The female-to-male (F/M) ratio of the patients was $6 / 4$, and the age range was 19-70 years (mean $=59$ ). All patients presented with occipitocervical pain and were operated using the midline lateral suboccipital approach.

RESULTS: One of the operated patients died in the intensive care unit due to upper gastrointestinal tract bleeding. Additionally, one patient had paresis in the early postoperative period, which resolved in the third follow-up month.

CONCLUSION: Foramen magnum meningiomas are operated safely by microsurgical methods using the midline lateral suboccipital approach after suboccipital triangle and vertebral artery are exposed.

KEYWORDS: Foramen Magnum, Meningiom, Suboccipital

ABBREVIATIONS: FMM: Foramen magnum meningioma, VA: Vertebral artery, CT: Computed tomography, SCM: Sternocleidomastoid

\section{INTRODUCTION}

$\mathrm{M}$ eningiomas account for $20 \%$ of all intracranial tumors. Foramen magnum meningiomas (FMMs) are an especially rare group among all meningiomas and constitute $1.5 \%-3.2 \%$ of the meningiomas $(4,6,7,22)$. They cause clinical symptoms by compressing the medulla spinalis and lower cranial nerves (5). Clinical findings include neck pain, dysesthesia, hyperreflexia, motor loss, imbalance, loss of heat and pain sensation, urinary incontinence, Brown-
Sequard syndrome, nystagmus, dysphagia, and headache. In particular, it is typical for motor impairments to occur first on the same side upper extremity, followed by the same side lower extremity, opposite side lower extremity, and opposite side upper extremity, in that order (11). Due to the large subarachnoid space at the foramen magnum level and the slow growth of their meningiomas, FMMs already reach large sizes before the manifestation of the symptoms. Advanced-age and non-symptomatic cases can be followed
Abidin Murat GEYIK (10) : 0000-0003-2166-9144

Serhat PUSAT (1) : 0000-0003-2412-2320

Mehmet ALPTEKIN (1) : 0000-0002-6665-7270
Berna KAYA UGUR (1) : 0000-0003-0044-363X

Sirma GEYIK (D): 0000-0003-0682-4302

Ali NEHIR (1) : 0000-0002-5311-7283
Ibrahim ERKUTLU (10) : 0000-0002-5749-1504 
due to high morbidity $(7,23)$. Radiosurgery is also used as an alternative treatment for small tumors (7). Today, in addition to microsurgical methods, extended endoscopic approaches are used. The first surgical intervention was performed by Elsberg and Strauss in $1930(1,5)$. FMMs are anatomically located in the anterior region between the lower clivus and the corpus of the C2 vertebra, the lateral jugular tubercle, occipital bone, and the spinose process of the C2 vertebra (Figure 1). FMM location can be intradural, intra-extradural, and extradural $(8,13)$. Although intradurally located lesions are common, there may also be entirely extradural lesions in rare cases. Various classifications have been made on the basis of adjacent anatomical structures in intradural FMMs. Bruneau and George made classifications based on the location of spinal dentate ligament. Accordingly, the tumor is classified as anterior FMM if its origin is between the anterior dura mater and the midline, lateral FMM if its origin is between the midline and the dentate ligament, and posterior FMM if its origin is in the dorsum of the dentate ligament $(5,9)$. This classification is important for preoperatively determining the surgical approach. Another classification has been made based on the tumor size. Accordingly, the tumor is classified as small if the its vertical diameter is less than $1 / 3$ of its horizontal diameter, medium if its vertical diameter is between $1 / 3$ and $1 / 2$ of its horizontal diameter, and large if its vertical diameter is larger than $1 / 2$ of its horizontal diameter. Additionally, a classification based on the adjacent vertebral artery (VA) classifies the tumor as an inferior tumor if it is below the VA, superior if it is above the VA, and bilateral if it is above and below the VA. This classification is also important in terms of showing the locations of the lower cranial nerves $(6,8,16)$. The first anatomical structure encountered when performing surgery in intradural meningiomas is the VA; additionally, the V3 and V4 segments should be known in detail when performing surgery in this region. The V3 segment enters into the dura in the occipitoatlantal dura mater region and forms the V4 segment.

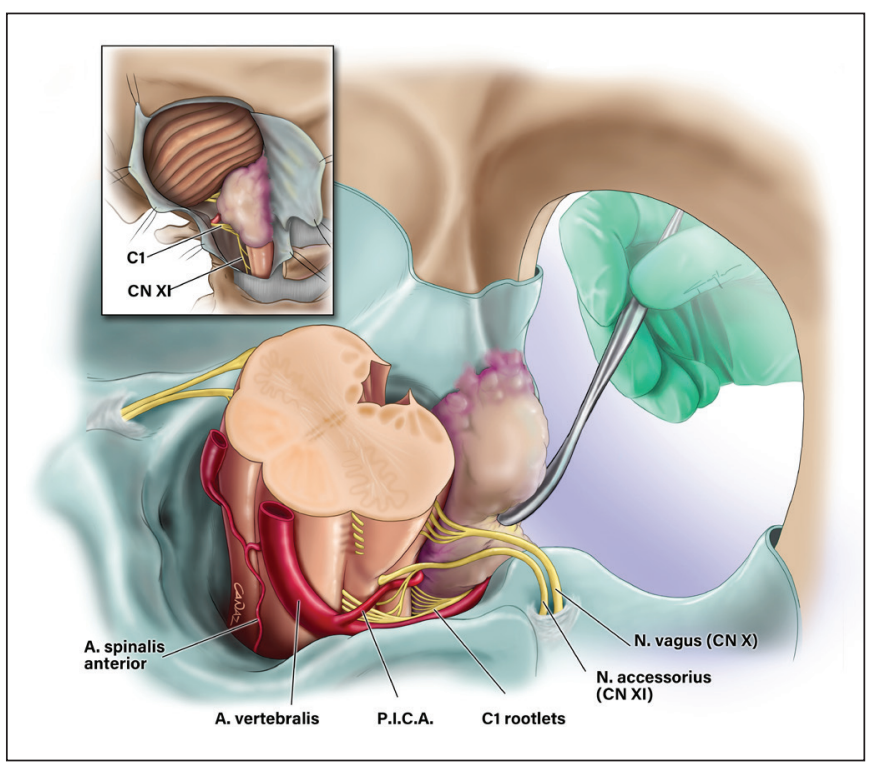

Figure 1: Illustrate foramen magnum meningiomas.
The VA, continuing to the superior, travels in the transverse process of the $\mathrm{C} 2$ vertebra and creates branches along its course. These include $\mathrm{C} 2$ radicular artery, posterior meningeal artery, and posterior spinal artery branches $(6,7)$. Suboccipital craniectomy and partial condylectomy were performed after the VA was surgically exposed during this course. The anatomical structures encountered after opening the dura mater in a $\mathrm{J}$ shape are the $9^{\text {th }}, 10^{\text {th }}$, and $11^{\text {th }}$ cranial nerves. The rootlets of these lower cranial nerves originate from the postolivar sulcus, pass through the jugular foramen, and travel in the dorsum of the VA $(6,21,24)$. The $12^{\text {th }}$ cranial nerve originates from the preolivar sulcus, turning anterolaterally and passing through the hypoglossal canal. Rarely, the VA divides the $12^{\text {th }}$ cranial nerve $(19,24)$. These structures should be identified during surgery and carefully removed from the tumor.

\section{MATERIAL and METHODS}

\section{Patients}

This study is a retrospective analysis of patients with FMMs who were operated in Gaziantep University, Faculty of Medicine, in Turkey between 2014 and 2019. The female-tomale (F/M) ratio of the operated patients was $6 / 4$, and the age range was $19-70$ years (mean $=59$ ). The duration of symptoms was between 8 and 34 months. Headache score was Nurick grade 2 for 5 patients and Nurick grade 3 for 5 patients. Only one patient had pyramidal tract findings, and no patient had lower cranial nerve involvement. Additionally, no patient had extradural spread. Gross total resection was achieved in all patients, and no reoperation was performed (Table I).

\section{Radiological Findings}

In the radiological evaluation, three patients had hydrocephalus, with none of the lesions below the $\mathrm{C} 1$ vertebra level. All patients were evaluated preoperatively with thin-slice $(0.3$ $\mathrm{mm}$ ) computed tomography (CT). This included the evaluation of the structure of the craniocervical junction, its adjacent structures, intratumor calcification, and the surgical corridor. In addition, the dominant VA trace, VA branches, and its relation with the lesion were evaluated using $C T$ angiography performed in the same session. Embolization was not used in any preoperative case (Figure 2).

\section{Surgery}

There is still no standard approach for surgical treatment of FMMs. We used the standard midline suboccipital approach in all patients we operated on. The patients were operated in the lateral decubitis position with their head placed on a head holder and turned toward the opposite side of the lesion. No inhaled anesthetic agents and muscle relaxants were used. Patients were monitored with real-time neuromonitorization, and instant changes were recorded. Two types of incisions can be used here: first is the C-shaped incision that extends from just above the inion to the bottom of the mastoid cells, second is the incision made in the shape of a classic hockey stick. We used hockey-stick incisions. The two muscles exposed after the incision are the sternocleidomastoid (SCM) 
Table 1: Demographic Characteristics and Pre/Postoperative Conditions of the Patients

\begin{tabular}{|c|c|c|c|c|c|c|}
\hline $\begin{array}{c}\text { Patient } \\
\quad \#\end{array}$ & Gender & $\begin{array}{c}\text { Age } \\
\text { (years) }\end{array}$ & Preoperative Condition & $\begin{array}{c}\text { Preoperative } \\
\text { mRs }\end{array}$ & Postoperative Status & $\begin{array}{c}\text { Postoperative } \\
\text { mRs }\end{array}$ \\
\hline 1 & M & 70 & Left side hemiparesis & 2 & $\begin{array}{l}\text { Improved hemiparesis mild } \\
\text { neck pain }\end{array}$ & 1 \\
\hline 2 & $\mathrm{~F}$ & 57 & Headache, Neck Pain & 1 & --- & 0 \\
\hline 3 & $\mathrm{~F}$ & 62 & Headache, Right Monoparesis & 1 & Headache & 0 \\
\hline 4 & $\mathrm{~F}$ & 55 & Headache & 1 & --- & 0 \\
\hline 5 & $\mathrm{~F}$ & 60 & Right Side Hemiplegia & 3 & Death (Gastroint. Bleeding) & 6 \\
\hline 6 & $\mathrm{~F}$ & 63 & Headache, Left Monoparesis & 1 & Headache & 0 \\
\hline 7 & $\mathrm{~F}$ & 59 & Headache, Neck Pain & 1 & Headache & 0 \\
\hline 8 & M & 19 & Headache & 1 & Headache & 0 \\
\hline 9 & $\mathrm{~F}$ & 51 & Headache,Right Side Hemiparesis & 2 & Improved hemiparesis & 1 \\
\hline 10 & $\mathrm{~F}$ & 34 & Headache, Neck Pain & 1 & Headache & 0 \\
\hline
\end{tabular}

mRs: Modified Rankin Scale.

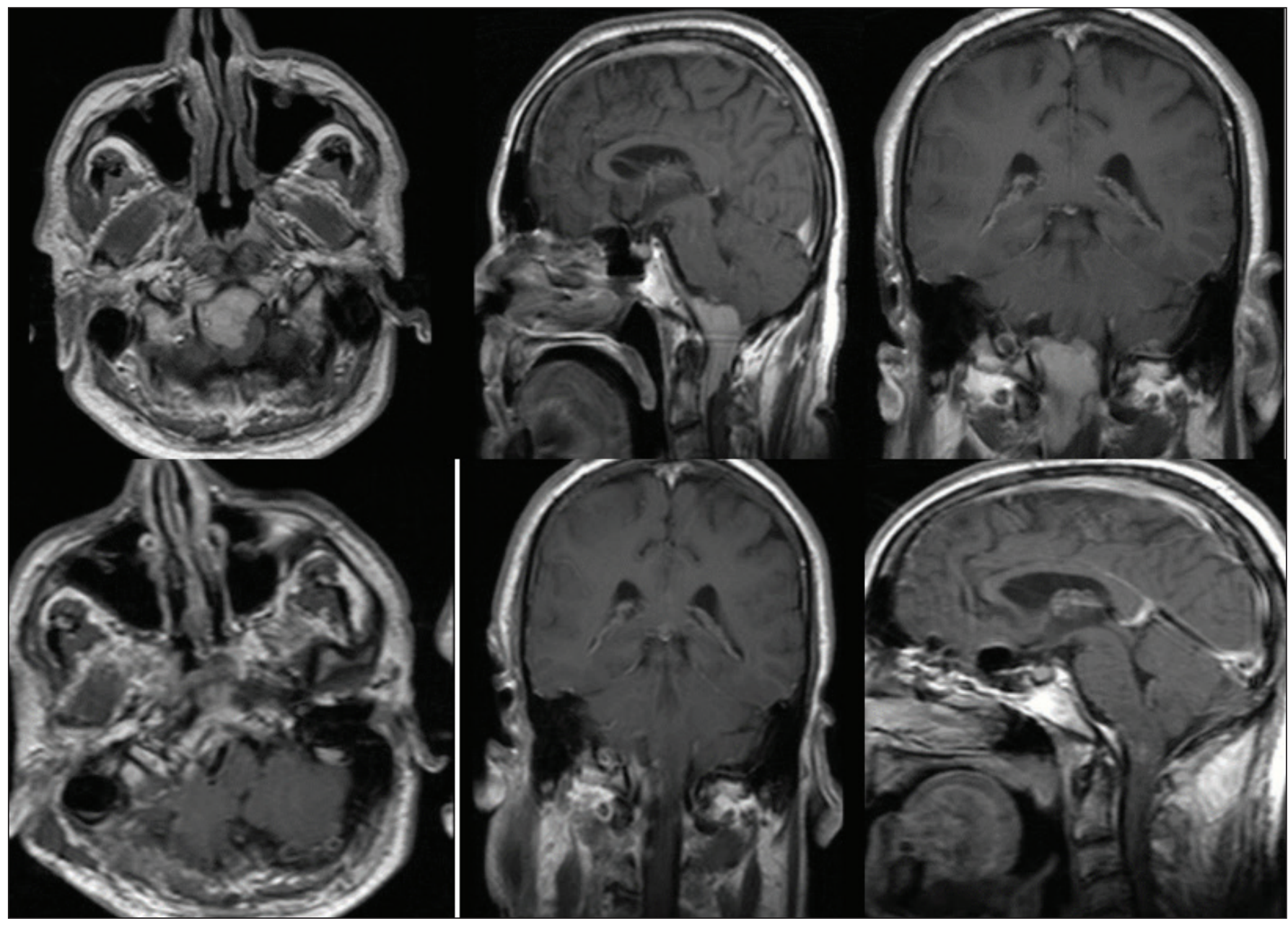

Figure 2: Preoperatif and postoperatif MR imagines. 
and splenius capitis muscles. While stripping the SCM muscle, the most important point is the inferior spinal accessory nerve. Monopolar cautery was not used to control local bleeding to avoid unexpected complications in the VA. In some studies, muscle contractions were prevented by injecting a mixture of $1 \%$ lidocaine epinephrine into the spinal accessory nerve to prevent contraction of the sternocleidomastoid and trapezius muscles (13). After the muscles were stripped, the burr hole was made to the level of protuberantia occipitalis externa. From here, a suboccipital craniotomy was performed by advancing to the foramen magnum. It should be noted that a VA is present just below the occipital condyles, which should be stripped very carefully during craniotomy (17). Subsequently, while $\mathrm{C} 1$ vertebra posterior lamina was stripped subperiosteally, subperiosteal stripping was performed from medial to lateral and inferior to superior without burning the venous plexuses as much as possible (11). The C1 vertebra posterior lamina was completely removed. C2 laminectomy was not required in any of our cases. Condylar resection was performed after the VA was exposed. While conducting condylar resection, approximately $1 / 3$ of the medial part of the condyle is removed. The most important step during condylar drilling is to protect the VA. In the literature, VA mobilization or the use of clips beforehand has been recommended (5). However, we did not use these methods to protect VA during surgery. In addition, the hypoglossal nerve was protected in all cases during 1/3 condylar resection. The dura was opened in an inverted $Y$ shape by bringing a microscope to the area. Firstly, the dura mater was opened in the cervical region where there was no tumor; tumor tissue and intact tissue could be differentiated, and cerebrospinal fluid (CSF) flow was provided before resection. After the CSF was drained, the tumor was reached by advancing through the subtonsillar space. C1 root was sacrificed in some cases depending on the size of the tumor. The spinal cord was mobilized by cutting the dentate ligament. After the tumor was dissected from the lower cranial nerves and VA, total resection was achieved first after intratumoral reduction. Ultrasonic aspirator was used for intratumor reduction, which was greatly beneficial. After the dura mater was sewn in a waterproof manner, surgical tissue glue was applied on it. No cranioplasty procedure was performed on the patients.

\section{Result}

Postoperatively, the patients were evaluated according to the modified Rankin scale. The mean follow-up period of the patients was 37 months (10-70 months). No patient experienced recurrence. The most rapidly resolving signs in the patients were loss of strength and occipitocervical pain. In a patient, whose motor strength had deteriorated clinically, it was observed that the motor strength returned to preoperative levels during the follow-up period. Additionally, during follow up in the postoperative intensive care unit, a patient experienced bleeding in the upper gastrointestinal tract and died. No patient experienced occipitocervical insufficiency based on the radiographic examination performed in the postoperative period (Table II).
Table II: Tumor Parameters

\begin{tabular}{lcc}
\hline Localization & Size $^{*}$ & Pathology \\
\hline PL 5 & S 2 & Meningioma \\
\hline L 2 & M 6 & Who Grade 1 \\
\hline P 2 & L 2 & \\
\hline
\end{tabular}

$\mathrm{AL} 1$

PL: Posterolateral, L: Lateral, P: Posterior, AL: Anterolateral

Vertical/Horizontal Diameter; $X$

S: Small $X<1 / 2$; M: Medium 1/2<X<1/3; L: Large $X>1 / 2$

\section{DISCUSSION}

Meningiomas are the most common tumors among intracranial tumors. While FMMs account for 2\%-3\% of all meningiomas, they constitute $4 \%$ of posterior fossa meningiomas $(3,9)$. FMMs cause clinical manifestations like asymmetric motor loss, dysesthesia, ataxia, and lower cranial nerve signs. FMMs are tumors associated with high mortality and morbidity due to their close proximity to the brainstem, lower cranial nerves, and VA. Because retraction or transposition of adjacent neural and vascular structures is almost impossible, their surgery is very difficult. As FMMs are generally slow growing lesions, they may have reached large sizes at the time of diagnosis. MRI is the gold standard for diagnosis. Access to anterior and anterolateral tumors is difficult, especially due to the lower cranial nerves. During surgery, the VA and, especially, the $12^{\text {th }}$ cranial nerve make the excision of the lesion difficult. Suboccipital midline approach is generally used in surgery. In addition, anterior transoral, lateral transcervical, or suboccipital posterolateral approach can be used $(7,12,15,18)$. Anterior approach is preferred for lesions ventral to the foramen magnum. Transoral or lateral cervical intervention can be performed. Rapid access to the lesion is an important advantage in the transoral approach. Tumor removal from the anterior transoral route by endoscopic methods in small sized tumors has been reported in the literature. However, CSF fistula formation and cervicobasal insufficiency are potential complications $(7,11)$. The lateral transcervical route is from the retropharyngeal area and is not used routinely in neurosurgery practice $(2,7)$. Additionally, FMMs can be approached from the presigmoid area. In the presigmoid transpetrosal approach, the possibility of injury, especially to the facial nerve, is high. In addition, extensive bone resection and petrosectomy may be required. Posterior approach is the preferred method as it provides easier and better vision (7). To date, various modifications have been made in the midline suboccipital far lateral approach. While making these modifications, the most important anatomical structure is the occipital condyles. Condyles can be removed completely, and transcondylar resection can be performed $(7,14)$. Removal of condyles and C1 vertebra transverse process during transcondylar resection causes serious instability and insufficiency in the occipitocervical region. Instead, the far lateral supracondylar approach is more appropriate to keep the occipitocervical stability constant. In this approach, stability can be maintained because only $1 / 3$ 
of the condyles are removed. In addition, as it provides an approach with a lateral angle, the lesion can be accessed without ruling out brainstem formations. Postoperative CSF fistula and hydrocephalus are likely to occur in the posterior suboccipital approach $(7 \%-22 \%)$ (13). It can be treated with postoperative lumbar drainage or ventriculoperitoneal shunt. In addition, conditions, including dysphagia and dystonia, may occur due to the effect of surgery on lower cranial nerves. In large tumors, subtotal resection and use of postoperative radiotherapy are also recommended to prevent postoperative tracheostomy and gastric feeding. In cases with a postoperative MIB-1 index of less than $7 \%$, some clinics do not use radiotherapy, but only use observation (13).

\section{CONCLUSION}

FMMs are very important tumors due to their neurovascular environment, and midline suboccipital approach is the preferred method in the surgery of these tumors.

\section{ACKNOWLEDGEMENTS}

We want to thanks "Cura Caraz Medical Arts" for medical illustration.

\section{REFERENCES}

1. Al-Mefty O: Foramen Magnum Meningiomas, Meningiomas. New York: Roven Press,1991:543-568

2. Arnautovic $\mathrm{KI}$, Al-Mefty $\mathrm{O}$, Husain $\mathrm{M}$ : Ventral foramen magnum meningiomas. Neurosurg 92 Suppl 1:71-80, 2000

3. Bilgin E, Cavus G, Acik V, Arslan A, Olguner SK, Istemen I, Gezercan Y, Okten Al: Our surgical experience in foramen magnum meningiomas: Clinical series of 11 cases. Pan Afr Med J 3:34-35, 2019

4. Bruneau M, George B: Classification system of foramen magnum meningiomas. J Craniovertebr Junction Spine 1:1017, 2010

5. Bruneau M, George B: Foramen magnum meningiomas: Detail surgical approaches and technical aspect at Lariboisiere Hospital and review of the literatüre. Neurosurg Rev 31:19-33, 2008

6. David CA, Spetzler RA: Foramen magnum meningiomas. Clin Neurosurg 44:467-489, 1997

7. Dobrowolski S, Ebner F, Lepski G, Tatagiba M: Foramen magnum meningioma: The midline suboccipital subtonsillar approach. Clin Neurol Neurosurg 145:28-34, 2016

8. Elsberg CA, Strauss I: Tumors of the spinal cord which project into the posterior cranial fossa. Report of a case in which a growth was removed from the ventral and lateral aspect of the medulla oblangata and upper cervical cord. Arch Neurol Pscyhiatry 21:261-273, 1929

9. Giordana M, Dugoni D, Bertalogffy $\mathrm{H}$ : Improving results in patients with foramen magnum meningiomas by translating surgical experience into a classification system and complexity score. Neurosurg Rev 42(4): 859-866, 2019
10. Kandenwein JA, Richter HP, Antoniadis G: Foramen magnum meningiomas-experience with the posterior suboccipital approach. Br J Neurosurg 23(1):33-39, 2009

11. Komotar RJ, Zacharia BE, McGovern RA, Sisti MB, Bruce JN, D'Ambrosio AL: Approaches to anterior and anterolateral foramen magnum lesions: A critical review. J Craniovertebr Junction Spine 1(2):86-99, 2010

12. Lynch JC, Gonçalves MB, Pereira CE, Welling L: Lateral suboccipital retrosigmoid retrocondylar approach for foramen magnum meningiomas. J Craniovertebral Junction Spine 9(3):175-181, 2018

13. Magill ST, Shahin MN, Lucas CHG, Yen AJ, Lee DS, Raleigh DR, Aghi MK, Theodosopoulos PV, McDermott MW: Surgical outcomes, complications, and management strategies for foramen magnum meningiomas. J Neurol Surg B Skull Base 80(1):1-9, 2019

14. Merezes AH, Traynelis VC, Gantz BJ: Surgical approaches to the craniovertebral junction. Clin Neurosurg 41:187-203,1994

15. Miller E, Crocked HA: Transoral transclival removal of anteriorly placed meningiomas at the foramen magnum. Neurosurgery 6:966-968, 1987

16. Mostafi K: Foramen magnum meningioma: Some anatomical and surgical remarks through five cases. Asian Spine J 9(1):54-58, 2015

17. Narava V, Agarwalla P, Jumah F, Nanda A: Far-lateral skull base approaches: Shades of grey. Neurol India 67(1):61-64, 2019

18. Pamigrahi $\mathrm{M}$, Vooturi $\mathrm{S}$ : Foramen magnum meningiomas. Understanding the requirement and extent of condylar resection. Neurology India 67(1):65-66, 2019

19. Pamir MN, Kilic T, Ozduman K, Ture U: Experience of a single institution treating foramen magnum meningiomas. J Clin Neuroscience 11(8):863-867, 2004

20. Pirotte BJM, Brotchi J, DeWitte O: Management of anterolateral foramen magnum meningiomas: Surgical vs conservative decision making. Neurosurgery 67 Suppl Operative 3:ons5870; discussion ons70., 2010

21. Rhoton AL Jr: The cerebellopontine angle and posterior fossa cranial nerves by the retrosigmoid approach. Neurosurgery 47 Suppl 3:S93-129, 2000

22. Rhoton AL Jr: The foramen magnum. Neurosurgery 47 Suppl 3:S155-193, 2000

23. Srinivas D, Sarma P, Deora H, Beniwal M, Vikas V, Rao KVLN, Chandramouli B A, Somanna S: "Tailored"' far lateral approach to anterior foramen magnum meningiomas-The importans of condylar preservation. Neurol India 67(1):142-148, 2019

24. Williams SR, Juratli TA, Castro BA, Lazaro T, Gill CM, Nayyar N, Strickland MR, Babinski M, Johnstone SE, Frosch MP, Silverman IM, Ely HA, Kaplan AB, D'Andrea MR, Bihun IV, Hoang K, Batchelor E, Christiansen J, Cahill DP, Barker FG, Brastianos PK: Genomic analysis of posterior fossa meningioma demonstrates frequent AKT1 E17K mutation in foramen magnum meningiomas. J Neurol Surg Skull Base 80(6):562-567, 2019 